\title{
Convex probe endobronchial ultrasound: historical, contemporary, and cutting-edge applications
}

\author{
Sameer K. Avasarala, Carlos Aravena, Francisco A. Almeida \\ Respiratory Institute, Cleveland Clinic, Cleveland, OH, USA \\ Contributions: (I) Conception and design: All authors; (II) Administrative support: None; (III) Provision of study materials or patients: None; (IV) \\ Collection and assembly of data: All authors; (V) Data analysis and interpretation: All authors; (VI) Manuscript writing: All authors; (VII) Final \\ approval of manuscript: All authors. \\ Correspondence to: Francisco A. Almeida, MD, MS. Respiratory Institute, Cleveland Clinic, 9500 Euclid Avenue, Cleveland, OH 44195, USA. \\ Email: almeidf@ccf.org.
}

\begin{abstract}
The use of convex-probe endobronchial ultrasound (CP-EBUS) has revolutionized bronchoscopy. It has provided the option of a relatively safe, minimally invasive approach for the assessment of various intrathoracic diseases. In current practice, its most dramatic impact has been on the diagnosing and staging of lung cancer. It has served as an invaluable tool that has replaced mediastinoscopy in a variety of clinical scenarios. Many pulmonologists and thoracic surgeons consider CP-EBUS the most significant milestone in bronchoscopy after the development of the flexible bronchoscope itself. In this review, we summarize the historical aspects, current indications, technical approach, and future direction of CP-EBUS.
\end{abstract}

Keywords: Bronchoscopy; lung cancer; lymphadenopathy; endobronchial ultrasound-guided transbronchial needle aspiration (EBUS-TBNA)

Submitted Jun 21, 2019. Accepted for publication Oct 24, 2019.

doi: $10.21037 /$ jtd.2019.10.76

View this article at: http://dx.doi.org/10.21037/jtd.2019.10.76

\section{Introduction}

Since the inception of endobronchial ultrasound, its use within thoracic medicine has become widespread in most developed countries. It has allowed for the use of a minimally invasive approach for the management of intrathoracic lymphadenopathy and lung lesions. Radial probe endobronchial ultrasound (RP-EBUS) and convex-probe EBUS (CP-EBUS) are two modalities of endobronchial ultrasound use within the tracheobronchial tree. In contemporary practice, RP-EBUS is performed with a radial probe (with or without a balloon), (Figure 1), which is advanced through the working channel of a bronchoscope. After processing, the ultrasound waves are translated into a 360-degree grey scale image (Figure 1). RP-EBUS is most commonly used for the evaluation of pulmonary nodules. Although it does allow real-time imaging, it unfortunately does not allow realtime guidance. Convex-probe EBUS also uses ultrasound technology to assist with imaging structures that are beyond the field of visualization of white light bronchoscopy. A convex ultrasound transducer is incorporated into the tip of the flexible bronchoscope; the transducer forms a grey-scale image that is parallel to the insertion of the bronchoscope (Figure 2) (1). A saline-filled balloon tip can be used to improve surface contact and enhance image quality. Doppler imaging can also be used to delineate vascular structures as well. The key differences between RP-EBUS and CP-EBUS are summarized in Table 1. One of the main advantages of CP-EBUS is its ability to provide realtime guidance when obtaining samples. When combined with concurrent transbronchial needle aspiration (TBNA), it has gained popularity in the diagnosis of intrathoracic lymphadenopathy as well as in the diagnosis and staging of lung cancer. Excluding the development of the fiberoptic bronchoscope itself, many consider endobronchial ultrasound-guided transbronchial needle aspiration 

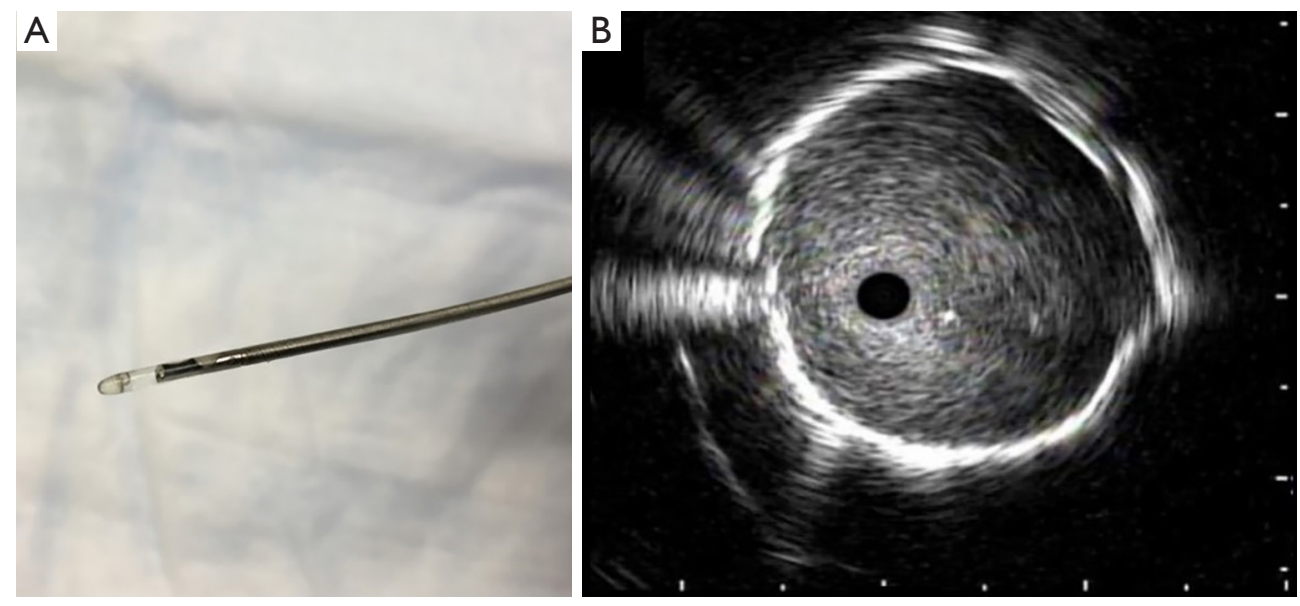

Figure 1 Key features of RP-EBUS. (A) A RP-EBUS probe can be advanced through the working channel of the bronchoscope to obtain and a $360^{\circ}$ greyscale image of parenchymal lesions, such as a lung nodule (B). RP-EBUS, radial probe endobronchial ultrasound.

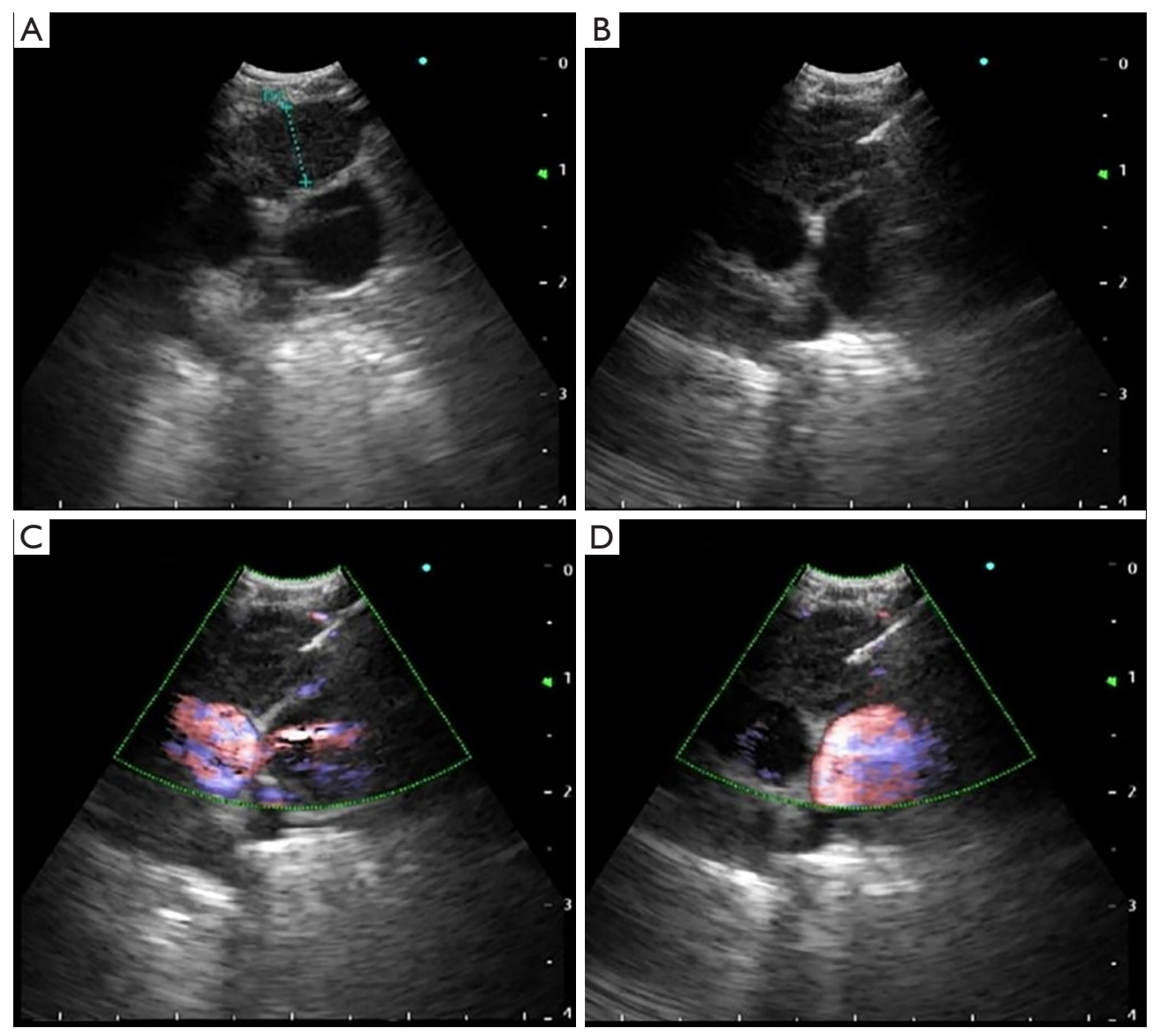

Figure 2 Key features of CP-EBUS. (A) The CP-EBUS is an excellent tool for visualizing and sampling (B,C,D) intrathoracic lymph nodes. Color Doppler can be used to assess for vascularity prior to and during sampling (C,D). CP-EBUS, convex probe endobronchial ultrasound. 
Table 1 Key differences between RP-EBUS and CP-EBUS

\begin{tabular}{lll}
\hline Characteristic & RP-RBUS & CP-EBUS \\
\hline Angle of view & $360^{\circ}$ & $90^{\circ}$ \\
Penetration & $4-5 \mathrm{~cm}$ & $>5 \mathrm{~cm}$ \\
Resolution & Comparatively worse & Comparatively better \\
Airway wall visualization & Yes, with balloon inflation & Yes, not as well studied \\
Doppler & No & Yes \\
Real-time sampling & No & Yes \\
\hline
\end{tabular}

RP-EBUS, radial probe endobronchial ultrasound; CP-EBUS, convex probe endobronchial ultrasound.

(EBUS-TBNA) as the greatest milestone in bronchoscopy history (2). In a number of clinical scenarios, it has either replaced or decreased significantly the use of mediastinoscopy. Convex-probe EBUS-TBNA is a safe procedure and is usually performed by pulmonologists or thoracic surgeons. Its benefits include its minimally invasive approach and ability to be performed under conscious sedation. In settings where rapid on-site evaluation (ROSE) is used, patients typically receive a preliminary diagnosis after the procedure. Even when general anesthesia is used, most cases can be conducted in an outpatient setting. A tool that was initially developed for evaluation of intrathoracic lymphadenopathy has proven to be useful in the management of a number of other thoracic diseases (3). It has been a research niche for thousands of people, the number publications describing EBUS-TBNA has risen exponentially (4). In this review, we discuss the history of CP-EBUS, its current application, and its future direction.

\section{Past}

Endoscopic ultrasound was first used within the field of gastroenterology for staging esophageal and gastric malignancies (5). Later, the use of ultrasound within the airways was developed in the early 1990s. These small ultrasound probes, also known as "miniprobes" were the first generation of radial probe EBUS (RP-EBUS) (6). In 2002, Herth et al. published the first report of using RPEBUS to guide transbronchial biopsies for the assessment of lung nodules (7). Although RP-EBUS was able to provide real-time images for biopsy planning, the actual biopsy was blind and had to be guided with imaging modalities such as fluoroscopy. As the importance of real-time biopsy guidance rose, the CP-EBUS was subsequently developed in 2002 (8).
Because the convex-probe EBUS has been used for the staging of lung cancer from its infancy its accuracy is often compared to what is seen with mediastinoscopy (9-11). The latter has been regarded as the gold standard for the mediastinal staging of non-small cell lung cancer (NSCLC). It typically allows access to the upper paratracheal (stations $2 \mathrm{R}$ and $2 \mathrm{~L}$ ), lower paratracheal (stations $4 \mathrm{R}$ and $4 \mathrm{~L}$ ) and subcarinal (station 7) lymph nodes (12). Overall, it is safe; the reported complication rate is up to $2.5 \%$ (pneumothorax, infection, and injury to nearby structures [vessels, nerves, bronchi, and esophagus]), mortality rate is estimated to be $0.08 \%$ (mostly being driven by injury to major vascular structures) (13). Due to the use of more minimally invasive techniques, rates of mediastinoscopy have been falling in the United States. One study indicated that the median center rate for mediastinoscopy being performed dropped from $21.6 \%$ to $10 \%$ between 2006 and 2010 (14). When compared to EBUS-TBNA, standard cervical mediastinoscopy has more complications, unequivocally requires general anesthesia and a small incision at/above the suprasternal notch, is more expensive, and has a higher risk and rate of complications (15). In addition, data shows endosonographic assessment of lymphadenopathy [EBUS-TBNA/endoscopic ultrasound fine needle aspiration (EUS-FNA)] has a similar yield but with lower complication rates when compared to mediastinoscopy for the mediastinal staging of NSCLC (16).

It is the culmination of these important factors that set the foundation for CP-EBUS to rise in popularity and achieve widespread use.

\section{Present}

At present, there are three companies [Olympus America ${ }^{\circledR}$ 

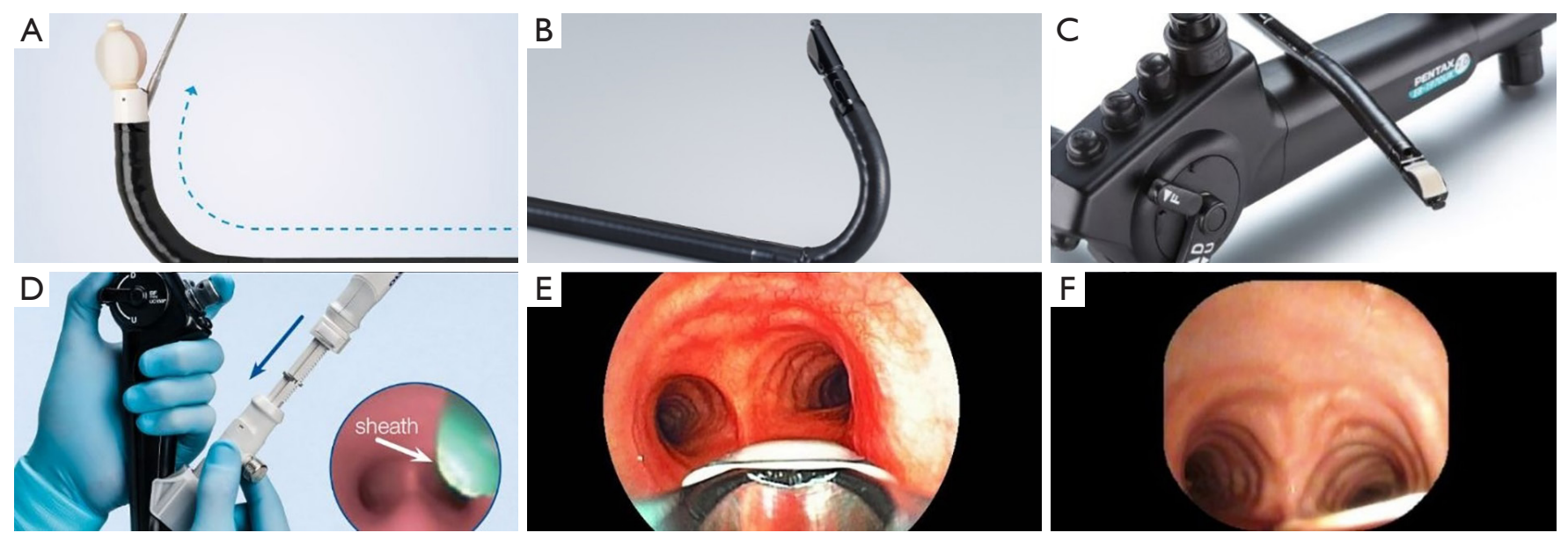

Figure 3 There are three CP-EBUS bronchoscopes currently available on the market: (A) Olympus ${ }^{\odot}$, (B) Fujifilm ${ }^{\odot}$, and $(\mathrm{C}) \mathrm{Pentax}^{\odot}$. The most significant difference between the bronchoscopes is the viewing angle: (D) Olympus ${ }^{\odot}$, (E) Fujifilm ${ }^{\odot}$, and (F) Pentax ${ }^{\odot}$. CP-EBUS, convex probe endobronchial ultrasound.

Table 2 Salient features of CP-EBUS bronchoscopes currently available on the market

\begin{tabular}{llll}
\hline Characteristic & Olympus $^{\odot}$ & Pentax $^{\odot}$ & Fujifilm $^{\odot}$ \\
\hline Model(s) & BF-UC160-OL8, BF-UC180F & EB-1970UK & EB-530US \\
Scanning frequency* & $5,6,7.5,8,10$, or $12 \mathrm{MHz}$ & $5,7.5$, or $10 \mathrm{MHz}$ & $5,7.5,10$, or $12 \mathrm{MHz}$ \\
Distal outer diameter & $6.9 \mathrm{~mm}$ & $6.3 \mathrm{~mm}$ & $6.7 \mathrm{~mm}$ \\
Working channel size & 2.0 or $2.2 \mathrm{~mm}$ & $2.0 \mathrm{~mm}$ & $2.0 \mathrm{~mm}$ \\
Direction of view & $30^{\circ}$ forward oblique & $45^{\circ}$ forward oblique & $10^{\circ}$ forward oblique
\end{tabular}

*, availability of scanning frequency is dependent on the processor the bronchoscope is paired with. CP-EBUS, convex probe endobronchial ultrasound.

(Center Valley, PA, United States), Pentax Ricoh Imaging ${ }^{\odot}$ (Tokyo, Japan), and Fujifilm Holdings ${ }^{\odot}$ (Tokyo, Japan)] that produce the CP-EBUS bronchoscopes that are in current use (Figure 3). The bronchoscopes share a similar design and have a few unique features. The salient features are described in Table 2. In current practice, CP-EBUS is mainly used for the diagnosis and/or staging of NSCLC. In addition, there is a body of literature to support its use in diagnosing various diseases that may present with intrathoracic adenopathy such as lymphoma, sarcoidosis, and infectious diseases.

\section{Diagnosis and staging of NSCLC}

An important tenant within the evaluation of NSCLC is that diagnosis and staging be performed during the same procedure (i.e., EBUS-TBNA), especially in patients with any adenopathy. Strict attempts to promote this process appear to protect the patient from unnecessary diagnostic procedures (i.e., CT-guided fine needle aspiration in the setting of obvious nodal disease) and result in more rapid and accurate staging $(17,18)$. In fact, current expert panel recommendations state suspicious mediastinal lymphadenopathy should undergo staging evaluation by a needle technique such as EBUS-TBNA, EUS-FNA, or a combined approach $(19,20)$. In addition, these same guidelines recommend the least number of procedures should be performed for both the stating and diagnosis of suspected NSCLC (21). Unfortunately, studies have shown that failing to follow guideline-consistent care 
is not uncommon $(18,22)$. A large retrospective cohort study of over 15,000 patients with lung cancer showed that an exceedingly high number of patients with NSCLC (44\%) did not have the mediastinum sampled and relied on imaging only (22). When compared to chest CT (sensitivity $76.9 \% /$ specificity $55.3 \%$ ) or PET (80\%/70.1\%), EBUS-TBNA $(92.3 \% / 100 \%)$ is more accurate in staging intrathoracic lymph nodes (23). In the same study, the diagnostic accuracy of EBUS-TBNA was also higher (98\%) when compared to CT $(60.8 \%)$ or PET (72.5\%).

In addition to superior diagnostic performance when compared to imaging modalities alone, other minimally invasive methods can be used to augment EBUS-TBNA. In general, EBUS-TBNA can access several nodal stations: 2, 3P, 4, 7, 10, 11 and 12. Endoscopic ultrasound fine-needle aspiration typically allows access to stations $4 \mathrm{~L}, 7,8$, and 9 (24). Specifically, the addition of EUS-FNA allows access to stations 8 and 9, which are not accessible by EBUSTBNA. In a meta-analysis, the sensitivity of an EBUSTBNA and EUS-FNA approach is estimated to be $90 \%$ (25). The combination of which may provide the best option for a minimally invasive approach to stage lung cancer. In addition to intrathoracic adenopathy, there is data that demonstrates that EBUS-TBNA can be useful in sampling the left adrenal gland in patients with lung cancer (26).

In recent history, the molecular characterization of lung cancer has gained clinical significance. Newer treatment modalities target molecular pathways that are essential to the survival of malignant cells: epidermal growth factor receptor (gefitinib), anaplastic lymphoma kinase (certinib), ROS-1 (crizotinib), programmed death-ligand 1 (PD-1/PD-L1) (nivolumab), etc. The most novel of these targets is PD-1/PD-L1. PD-L1 positivity appears to be higher in certain patients with NSCLC: males, smokers, advanced pathologic stages, positive vessel invasion, and positive lymphatic invasion (27). Tissue specimens derived from EBUS-TBNA has been found to be reliable to perform molecular bio-marker analysis (28). However, this is dependent on the cutoff value used for a sample to be considered PD-L1 positive (29). A study by Sakata et al. showed that concordance rates between EBUS-TBNA derived samples and surgical lung biopsy samples range between $82-87 \%$. The concordance rates for PD-L1 $\geq 1 \%$ and $\geq 50 \%$ were $87 \%$ and $82 \%$, respectively (29). Sakakibara et al. also showed good concordance between EBUS-TBNA and the corresponding primary tumor in regard to PD-L1 positivity (30). In the current landscape of lung cancer therapy, immunotherapy is considered the cornerstone of management in advanced stages that can, ultimately, extend survival (31).

After appropriate diagnosis, staging and therapy, EBUSTBNA still maintains an important role in lung cancer management. It is the preferred modality for re-biopsy to assess for relapse after therapy or response after neoadjuvant treatment $(32,33)$. These re-biopsies are useful in detecting specific new mutations, which may have therapeutic implications (the use of osimertinib for T790M mutation for instance) (34).

\section{Lymphoma}

Endobronchial ultrasound-TBNA has also been shown useful in the diagnosis of lymphoma, albeit, with limitations. A study has shown that the sensitivity of EBUS-TBNA for the detection of lymphoma was $76 \%$; however, the sensitivity for the definitive diagnosis of lymphoma was only $57 \%$ (35). Lymphoma detection by EBUS-TBNA in another study was $65 \%$ (diagnostic sensitivity) and $96.1 \%$ (negative predictive value) (36). A more recent study quoted an overall sensitivity that was $85 \%$, but $91 \%$ for detection of recurrence (37). Overall, these were small studies; the body of medical literature suggests that the diagnostic accuracy of EBUS-TBNA for lymphoma is significantly lower than it is for lung cancer staging. The small volume of specimens obtained poses difficulties for confirming specific subtypes, which is key for formulating a treatment plan. Even with this potential limitation, it may be reasonable to consider using EBUS-TBNA in a patient suspected to have lymphoma with isolated mediastinal lymphadenopathy, in order to avoid a surgical biopsy.

At present, the American College of Chest Physicians Expert Panel states that EBUS-TBNA is an acceptable initial, minimally invasive diagnostic test for a patient with suspected lymphoma (38). It is important to keep in mind that this is an ungraded, consensus-based statement; there is not an agreement amongst international societies. The British Thoracic Society states that "at present, there is insufficient evidence to recommend EBUS-TBNA for routine use in the diagnosis of lymphoma" (39).

\section{Sarcoidosis}

Endobronchial ultrasound TBNA has been proven 
to be useful for evaluating benign causes of thoracic lymphadenopathy as well. It provides diagnostic information in patients with early stage sarcoidosis that have adenopathy, but minimal changes to the lung parenchyma (40). It should be kept in mind that a tissue diagnosis is not necessary for most patients with stage I (bilateral hilar lymphadenopathy) sarcoidosis and that clinical/radiological findings may be specific enough to secure a diagnosis (41-43). When compared to the conventional transbronchial biopsy, the yield of EBUS-TBNA in this clinical setting is higher. Gupta et al. suggest that EBUS-TBNA should be combined with transbronchial lung biopsies to optimize yield for sarcoidosis (44). A significant criticism of this study was the lack of ROSE in either arm (45).

Based on the results of the GRANULOMA study, endosonographic (EUS-FNA or EBUS-TBNA) the diagnosis of lower stage (I and II) of sarcoidosis was higher when compared to conventional bronchoscopy biopsy (transbronchial or endobronchial biopsy) (46). The diagnostic yield of granuloma detection was $80 \%$ in the endosonographic group vs. $53 \%$ in the standard bronchoscopy group.

Unfortunately the latest consensus statement regarding the diagnosis sarcoidosis by a multi-organizational group (American Thoracic Society, European Respiratory Society, and the World Association of Sarcoidosis and Other Granulomatous Disorders) was made several years prior to the development of EBUS-TBNA (47).

\section{Infectious diseases}

There are several infectious diseases that can present with intrathoracic lymphadenopathy. For example, both primary tuberculosis (TB) and post-primary $\mathrm{TB}$ can have intrathoracic lymphadenopathy. In fact, thoracic lymphadenopathy is an important radiographic feature of primary $\mathrm{TB}$ and is seen in $40 \%$ of adult cases and $90-95 \%$ of pediatric cases (48). In a meta-analysis of eight studies involving 809 patients with TB, the pooled sensitivity and specificity of EBUS-TBNA for the diagnosis of intrathoracic TB was $80 \%$ and $100 \%$ (49). In a similar light, the pooled sensitivity of EBUS-TBNA for diagnostic intrathoracic TB lymphadenitis was $87 \%$. The overall diagnostic sensitivity for intrathoracic TB was $80 \%$, sensitivity for TB lymphadenitis was $87 \%$ (49). The studies that were included in this meta-analysis were from China, Korea, Turkey, United Kingdom and Ireland. The geographic variability is importance since as prevalence of the disease may vary based on geographic location.

EBUS-TBNA has also been found to be useful in identifying the cause of granulomatous inflammation within intra-thoracic lymph nodes. In a study of 210 patients that underwent EBUS-TBNA, 56 were found to have granulomatous inflammation on histocytological evaluation (50). Twenty of these patients were found to have caseating granulomas of varying etiologies: histoplasma, Blastomyces, or mycobacterium TB.

There are useful applications amongst immunocompromised hosts as well. In patients with HIV, EBUS-TBNA itself had a diagnostic yield of $60.5 \%$. A diagnostic accuracy of $97.7 \%$ was present with the combination of transbronchial biopsy and EBUS-TBNA. The most common infectious organism in this cohort was TB (51).

Akin to other etiologies of thoracic lymphadenopathy, the data for EBUS-TBNA in diagnosing an infectious etiology is not as unequivocally proven as it is for lung and other solid cancers (52-54). In a study of 82 patients, the results suggested that EBUS-TBNA may not be sufficiently sensitive to rule out infectious causes of adenopathy. Only five percent of patients in this cohort had HIV. Only two patients had a bacterial culture from the EBUS-TBNA that was positive for an organism that could potentially be pathogenic. In addition, two more patients had a positive Mycobacterial culture (both for Mycobacterium aviumintracellulare) (55).

\section{Mediastinal lesions}

In contemporary practice, EBUS-TBNA can be used as a therapeutic intervention as well. If clinically indicated, a variety of mediastinal lesions can be accessed or sampled. In the case of a cyst in the mediastinum, full drainage may also be possible with EBUS-TBNA (56). Prior to procedural planning, a careful review of the chest CT can help formulate a differential diagnosis of what the lesion may be. Location of the mass in relation to the mediastinal compartment and its Hounsfield Units are useful clues. In a retrospective study of 140 patients with mediastinal masses of unknown etiology and no evidence of lung cancer or other pulmonary malignancy, EBUS-TBNA was diagnostic in 131 (93.6\%) of patients (57). It is unclear how many of these mediastinal masses could have been large intrathoracic lymph nodes. There are several case reports outlining the use of CP-EBUS for draining mediastinal lesions such as 

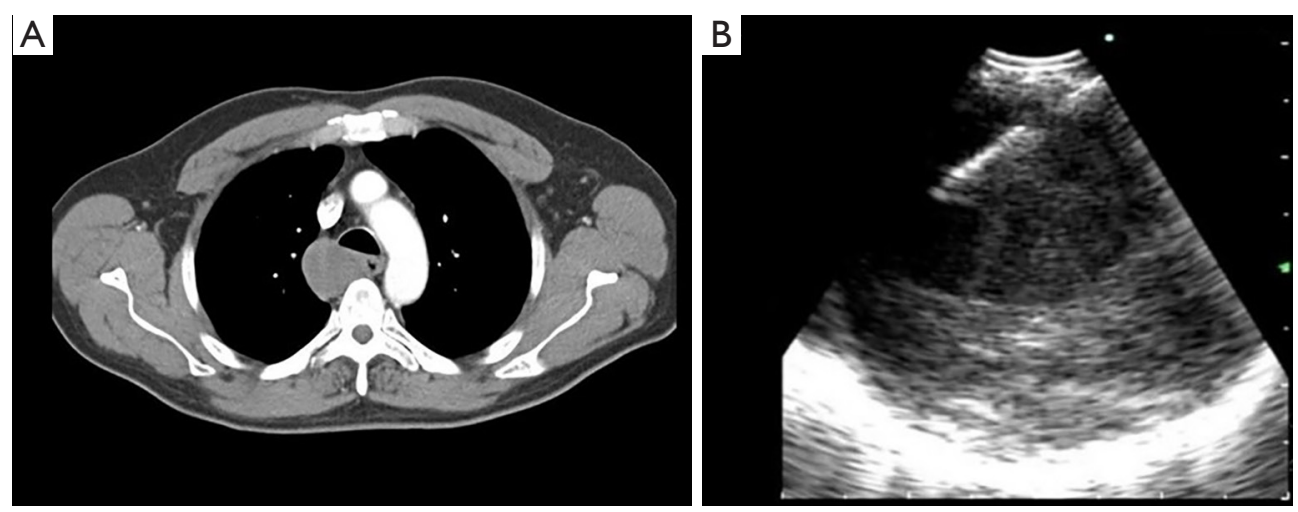

Figure 4 Convex probe endobronchial ultrasound is useful in the management of a variety of mediastinal pathology. (A) A middle mediastinal mass noted on contrast-enhanced chest CT; (B) it was visualized and sampled successfully with the use of CP-EBUS; the cytological results were consistent with an esophageal duplication cyst. CP-EBUS, convex probe endobronchial ultrasound.

esophageal duplications cysts (Figure 4), bronchogenic cysts, and pericardial effusions (58-60). It is important to note that these therapeutic applications of CP-EBUS are yet to be supported by robust data. In our own experience, complete therapeutic success is uncommon.

\section{Performing EBUS-TBNA in present day}

The success of EBUS-TBNA is predicated on a variety of factors: patient selection, available equipment, and the management of specimens (acquisition, processing, and interpretation). The procedural steps of EBUS-TBNA are outlined below. There are a lot of nuances within the described technique; there may be subtle differences in approach between any two bronchoscopists. The procedure can be performed under moderate sedation or with general anesthesia. Two commonly used airway devices include the endotracheal tube and the laryngeal mask airway. The type of anesthesia and the airway used can vary between bronchoscopists and centers.

\section{EBUS-TBNA procedural steps}

\section{Equipment}

The CP-EBUS bronchoscope is connected to an ultrasound processor that allows to record the patient information, measure the lesion, label, adjust the scanning range (the typical default $4 \mathrm{~cm}$ range permits to visualize best most of the hilar, mediastinal and vascular structures), regulate the gain to improve imaging, use of color/power flow to help identify vascular structures, or perform elastography to identify different strain/stiffness in the tissue (61-63). Several dedicated aspiration needles are available allowing real-time EBUS-TBNA. For optimization of the ultrasound (US) imaging, a latex balloon should be attached to the tip of the EBUS scope with a dedicated applicator forceps and be filled with 0.3 to $0.5 \mathrm{~mL}$ of saline if it is necessary during the procedure $(63,64)$.

\section{Insertion of the EBUS bronchoscope}

It is essential to know that the tip of the CP-EBUS scope may not be visible and the field of view depends on the type of bronchoscope used (Table 2). The quality of the image is lower than a conventional bronchoscope. In order to obtain a straight view, the tip of the scope needs to be flexed down (thumb up). Therefore, when the scope is advanced, the visualization must be slightly anterior, and in this way do not traumatize the posterior structures of the upper and lower airways.

If an endotracheal tube is not used, the scope must be passed throughout the vocal cords visualizing the anterior angle of the glottis. Never force the scope into the glottis, because the non-visible tip may cause dislocation of the cartilage (63). Passing through the vocal cords should occur with the tip of the bronchoscope slightly flexed anteriorly (thumb down). While it is advanced into the proximal airway the thumb should progressively push the control lever up, as it passes downwards, the upper trachea follows the curvature of the spine going slightly backward. Thus, the scope must follow its curvature to prevent any trauma; callousness in this step can lead to tears of the tracheal wall (Video 1). Posteriorly, the tip of the scope is adjusted to 
favor anterior visualization until it is positioned in the distal trachea.

\section{Finding the lymph node}

Once the EBUS scope is in the mid to distal trachea, the balloon is inflated with saline to optimize the US probe contact, wave transmission, and imaging. Visualization of areas such as the hilar and interlobar lymph nodes may only need a small amount of saline in the balloon (less than $0.5 \mathrm{~mL}$ ) or no balloon at all. Most other areas usually require use of the balloon with more than $0.5 \mathrm{~mL}$ of saline for best visualization. Due to the angulation of the airway, station $4 \mathrm{~L}$ can be difficult area for the EBUS scope to make contact $(63,65,66)$. Airway anatomic landmarks and vascular ultrasound imaging are used to identify the different stations $(65,66)$.

When an EBUS-TBNA staging is performed, to avoid contamination and upstaging, the starting station should be the contralateral hilum or mediastinum of the primary suspicious or known lung cancer location. This should be followed by staging of the lymph nodes of the contralateral mediastinum (if starting on the contralateral hilum), central/ ipsilateral mediastinum, and finally, the ipsilateral hilum. If evaluating a right lung lesion, the staging should start at station $11 \mathrm{~L}$ (or $4 \mathrm{~L} / 2 \mathrm{~L}$ ) and typically conclude with station 11R. A summary of the endoscopic locations of the various stations can be found in Table 3 .

\section{Sampling technique}

The aspiration needle is inserted through the instrument channel while the control lever is in a neutral position to avoid channel damage. The aspiration needle is secured in the scope, locking the connecting slider to the instrument channel port. The sheet adjuster knob is released, the adjuster is pushed down until the sheet is visible and the knob is tightened. After locating and positioning the target (most commonly) to the left of the US image (this can be changed based on operator's preference), the stopper is adjusted or removed, the needle adjuster is unlocked, and the needle slider is pushed down until the needle is advanced into the target. The needle will appear in the right upper corner of the US image and will advance obliquely down and to the left. When the needle is in the target, most operators will move the stylet up and down at least once to presumably eliminate the bronchial epithelium that passed into the needle, and the stylet is then pulled back about $15 \mathrm{~cm}$ or completely remove it. Data has shown that stylet use does not improve diagnostic yield in CP-EBUS (67). The suction system could be attached if is necessary and the needle is moved up and down 5 to 15 times into the target from its upper to the lower edge (capsule to capsule in a lymph node). Then, if the suction was attached, it must be turned off. The needle can be removed moving the sliding needle upwards until a click is felt for most commonly used needles; the needle adjuster is pushed up back into position and is locked. The bronchoscope must be in neutral position, the connecting slider is unlocked, and the aspiration needle can be withdrawn.

\section{Optimization and troubleshooting}

During EBUS-TBNA, penetration of the needle through the airway may push the airway away from the probe, which will result in loss of ultrasound imaging of the target. It can be resolved by asking the assistant to hold and push the bronchoscope lightly while the bronchoscopist introduces the needle into the lesion. When several hyperechoic parallel lines are observed in the US image, it means the US probe/balloon does not have enough contact with the airway wall. Re-positioning the EBUS probe or increasing the size of the balloon should resolve this problem.

In case of latex allergy, the procedure must be performed without the balloon (63). If imaging is not ideal, some authors recommend the use of a water-based lubricant to improve US visualization (64). For improvement of the suctioning, the working channel may be covered with a finger while the suction button is pressed. When the camera has a clot and cannot be suctioned, the balloon can be deflated, and the scope should be advanced to distal airway. The scope must be pulled up rubbing the walls while suctioning to clean the camera. When the insertion of the needle is difficult, sharpen the needle pulling up the stylet a millimeter cold help to ease the needle insertion. If a scant sample was obtained without suction, a vacuum pressure syringe could be used to improve the sample size. If suctioning was used and the ROSE showed a nondiagnostic bloody sample, next pass should be done without suctioning.

\section{Procedural billing}

Unfortunately, reimbursement within the United States has recently been reduced for EBUS (68). Due to federal reevaluation, reimbursement for an EBUS was lowered in the beginning of 2016. Based on an equation published in this study, it is estimated that almost $\$ 5,000$ in total revenue 
Table 3 Endoscopic locations of lymph nodes accessible by CP-EBUS

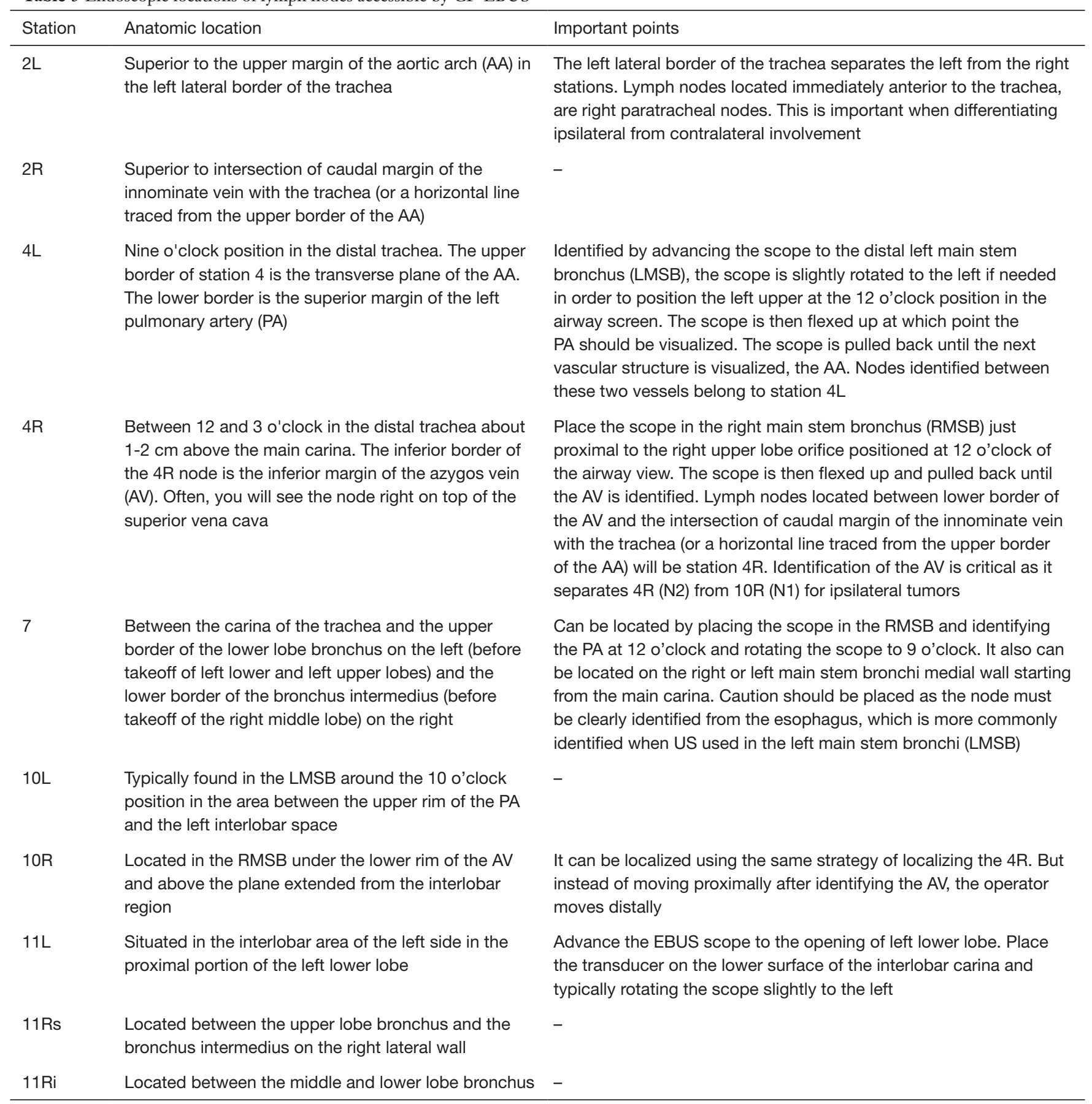

AA, aortic arch; LMSB, left main stem bronchus; PA, pulmonary artery; AV, azygos vein; RMSB, right main stem bronchus. 
(unadjusted for geographic practice cost index) would be lost for every 100 patients that underwent an EBUS procedure. When extrapolated to a high-volume center, this can equate to thousands of dollars of lost revenue every year.

\section{Future}

The future of CP-EBUS looks bright. Its current applications are well established; new indications are currently being evaluated. It is equally important to standardize EBUS training for the next generation of bronchoscopists.

\section{Standardization of training}

No two pulmonary training programs are alike. This has led to a significant degree of variance of a trainee's exposure to procedures such as CP-EBUS. At present the American Thoracic Society, American College of Chest Physicians, and European Respiratory Society recommend that a minimum of 40 to 50 supervised EBUS bronchoscopies are performed, before a trainee is ready for independent practice $(69,70)$. To maintain competency, it is recommended that at least 20 procedures are performed every year. The debate of the value of volume based competency for EBUS-TBNA is ongoing (71-73). It is suspected that most institutions do not track trainee EBUS-TBNA volume and do not follow ATS or CHEST recommendations (73). This has the potential of causing significant bottlenecks in the training of competent advanced diagnostic bronchoscopists in the years to come.

Recently, EBUS training has relied heavily on virtual simulators. There is data to support that bronchoscopy skills improve with early use of high-fidelity virtual simulators (74). The American College of Chest Physicians recommends that simulators be incorporated (low or high fidelity) in the training of EBUS-TBNA operators (Grade 2C) (38). They also recommend objective validated EBUS skills assessment tests be used to assess skill (ungraded, consensus-based statement) (38). The EBUS Skills and Task Assessment Tool (EBUS-STAT) has been validated as an objective assessment of skill level; it is the probably the most commonly used assessment tool (75). Other virtual realitybased assessment tools [Bronch Mentor ${ }^{\mathrm{TM}}$ (3D Systems, Littleton, Colorado, U.S.) and EndoVR ${ }^{\mathrm{TM}}$ Interventional Simulator (CAE Healthcare, Sarasota, Florida, U.S.)] have also been used to objectively assess EBUS-TBNA skills $(76,77)$. However, these require the purchase of expensive simulation machines.

\section{Cutting edge horizon}

The application of CP-EBUS continues to expand in breadth and depth. Recently, EBUS-TBNA has been shown to be effective in sampling intrapulmonary lesions, with a diagnostic yield close to $90 \%$ amongst 108 procedures (78).

Endobronchial ultrasound has also become useful in imaging the pulmonary artery. There are multiple case reports of pulmonary artery embolisms being diagnosed in patients who were undergoing CP-EBUS (79-81). In conventional teaching, one of the main advantages of CP-EBUS is the real time visualization and avoidance of adjacent vascular structures during a needle aspiration. In recent history, CP-EBUS has been used to visualize and diagnose primary and metastatic pulmonary artery tumors $(82,83)$.

The field of lung cancer chemotherapy is also reaping the benefits of CP-EBUS. Currently there is ongoing research into the effectiveness of EBUS transbronchial bronchial needle injection delivery of chemotherapy to treat locoregional recurrence of lung cancer (84).

The next generation of CP-EBUS is still under development. It is noted to be smaller, have sharper needle angles, decreased forward oblique view, and more flexible angulation range (85). Thin CP-EBUS probes are hopefully going to allow the operator to assess distal N1 nodes and more distal intrapulmonary lesions. When these bronchoscopes were used among five ex vivo human lungs that were declined for lung transplantation, they demonstrated a $22.1 \mathrm{~mm}$ greater maximum reach and 10.3 further endoscopic visibility range when compared to the current, standard size CP-EBUS (86). Subsegmental lymph nodes could be accessed. The lymph nodes in this study were sampled via the use of a prototype $25 \mathrm{G}$ aspiration needle.

\section{Conclusions}

Convex probe EBUS is an essential tool for advanced diagnostic pulmonologists, interventional pulmonologists, and thoracic surgeons with applications that have become more versatile since its inception. Many consider it one of the major landmarks in the history of bronchoscopy. In 
this current day and age, it is rare that mediastinoscopy is performed for evaluation of thoracic lymphadenopathy where EBUS is available. In fact, mediastinoscopy in lung cancer staging may become obsolete in the years to come. There are current, ongoing trials to assess whether mediastinoscopy should even be considered after a negative endosonographic evaluation of intrathoracic lymph nodes for the staging of patients with NSCLC (87).

In summary, studies over the past two decades have proven EBUS's usefulness in the diagnosis and staging of lung cancer as well as the diagnosis of other causes of mediastinal and hilar lymphadenopathy. The procedure has been proven to be efficacious, cost-effective, and safe. With the continued advancement of biomedical engineering and imaging technology, we anticipate more applications to come to light.

\section{Acknowledgments}

Funding: None.

\section{Footnote}

Provenance and Peer Review: This article was commissioned by the Guest Editor (Kassem Harris) for the series "Interventional Pulmonology" published in Fournal of Thoracic Disease. The article was sent for external peer review organized by the Guest Editor and the editorial office.

Conflicts of Interest: The series "Interventional Pulmonology" was commissioned by the editorial office without any funding or sponsorship. The authors have no other conflicts of interest to declare.

Open Access Statement: This is an Open Access article distributed in accordance with the Creative Commons Attribution-NonCommercial-NoDerivs 4.0 International License (CC BY-NC-ND 4.0), which permits the noncommercial replication and distribution of the article with the strict proviso that no changes or edits are made and the original work is properly cited (including links to both the formal publication through the relevant DOI and the license). See: https://creativecommons.org/licenses/by-nc-nd/4.0/.

\section{References}

1. Yasufuku K, Nakajima T, Chiyo M, et al. Endobronchial ultrasonography: current status and future directions. J Thorac Oncol 2007;2:970-9.

2. Bade B, Furukawa B, Tanner NT. Convex probe endobronchial ultrasound. Semin Respir Crit Care Med 2014;35:636-44.

3. Yasufuku K, Chiyo M, Sekine Y, et al. Real-time endobronchial ultrasound-guided transbronchial needle aspiration of mediastinal and hilar lymph nodes. Chest 2004;126:122-8.

4. Fernandez-Villar A, Mouronte-Roibas C, Botana-Rial $M$, et al. Ten Years of Linear Endobronchial Ultrasound: Evidence of Efficacy, Safety and Cost-effectiveness. Arch Bronconeumol 2016;52:96-102.

5. Gompelmann D, Eberhardt R, Herth FJ. Endobronchial ultrasound. Endosc Ultrasound 2012;1:69-74.

6. Schuhmann M, Eberhardt R, Herth FJF. Endobronchial ultrasound for peripheral lesions: a review. Endosc Ultrasound 2013;2:3-6.

7. Herth FJ, Ernst A, Becker HD. Endobronchial ultrasound-guided transbronchial lung biopsy in solitary pulmonary nodules and peripheral lesions. Eur Respir J 2002;20:972-4.

8. Yang H, Zhang Y, Wang KP, et al. Transbronchial needle aspiration: development history, current status and future perspective. J Thorac Dis 2015;7:S279-86.

9. Adams K, Shah PL, Edmonds L, et al. Test performance of endobronchial ultrasound and transbronchial needle aspiration biopsy for mediastinal staging in patients with lung cancer: systematic review and meta-analysis. Thorax 2009;64:757-62.

10. Varela-Lema L, Fernandez-Villar A, Ruano-Ravina A. Effectiveness and safety of endobronchial ultrasoundtransbronchial needle aspiration: a systematic review. Eur Respir J 2009;33:1156-64.

11. Gu P, Zhao YZ, Jiang LY, et al. Endobronchial ultrasoundguided transbronchial needle aspiration for staging of lung cancer: a systematic review and meta-analysis. Eur J Cancer 2009;45:1389-96.

12. Czarnecka-Kujawa K, Yasufuku K. The role of endobronchial ultrasound versus mediastinoscopy for nonsmall cell lung cancer. J Thorac Dis 2017;9:S83-S97.

13. Toloza EM, Harpole L, Detterbeck F, et al. Invasive staging of non-small cell lung cancer: a review of the current evidence. Chest 2003;123:157s-66s.

14. Vyas KS, Davenport DL, Ferraris VA, et al. Mediastinoscopy: trends and practice patterns in the United States. South Med J 2013;106:539-44.

15. Hegde PV, Liberman M. Mediastinal Staging: 
Endosonographic Ultrasound Lymph Node Biopsy or Mediastinoscopy. Thorac Surg Clin 2016;26:243-9.

16. Sehgal IS, Dhooria S, Aggarwal AN, et al. Endosonography Versus Mediastinoscopy in Mediastinal Staging of Lung Cancer: Systematic Review and MetaAnalysis. Ann Thorac Surg 2016;102:1747-55.

17. Almeida FA, Uzbeck M, Ost D. Initial evaluation of the nonsmall cell lung cancer patient: diagnosis and staging. Curr Opin Pulm Med 2010;16:307-14.

18. Almeida FA, Casal RF, Jimenez CA, et al. Quality gaps and comparative effectiveness in lung cancer staging: the impact of test sequencing on outcomes. Chest 2013;144:1776-82.

19. De Leyn P, Dooms C, Kuzdzal J, et al. Revised ESTS guidelines for preoperative mediastinal lymph node staging for non-small-cell lung cancer. Eur J Cardiothorac Surg 2014;45:787-98.

20. Detterbeck FC, Lewis SZ, Diekemper R, et al. Executive Summary: Diagnosis and management of lung cancer, 3rd ed: American College of Chest Physicians evidence-based clinical practice guidelines. Chest 2013;143:7s-37s.

21. Rivera MP, Mehta AC, Wahidi MM. Establishing the diagnosis of lung cancer: Diagnosis and management of lung cancer, 3rd ed: American College of Chest Physicians evidence-based clinical practice guidelines. Chest 2013;143:e142S-e65S.

22. Ost DE, Niu J, Elting LS, et al. Quality gaps and comparative effectiveness in lung cancer staging and diagnosis. Chest 2014;145:331-45.

23. Yasufuku K, Nakajima T, Motoori K, et al. Comparison of endobronchial ultrasound, positron emission tomography, and CT for lymph node staging of lung cancer. Chest 2006;130:710-8.

24. Nasir B, Cerfolio RJ, Bryant AS. Endobronchial ultrasound (EBUS) with tranbronchial needle aspiration (TBNA) versus mediastinoscopy for mediastinal staging in non-small cell lung cancer (NSCLC) thoracic cancer. Thorac Cancer 2012;3:131-8.

25. Dhooria S, Aggarwal AN, Gupta D, et al. Utility and Safety of Endoscopic Ultrasound With BronchoscopeGuided Fine-Needle Aspiration in Mediastinal Lymph Node Sampling: Systematic Review and Meta-Analysis. Respir Care 2015;60:1040-50.

26. Crombag LM, Annema JT. Left Adrenal Gland Analysis in Lung Cancer Patients Using the Endobronchial Ultrasound Scope: A Feasibility Trial. Respiration 2016;91:235-40.
27. Miyazawa T, Marushima H, Saji H, et al. PD-L1 Expression in Non-Small-Cell Lung Cancer Including Various Adenocarcinoma Subtypes. Ann Thorac Cardiovasc Surg 2018.

28. Minami D, Ozeki T, Okawa S, et al. Comparing the Clinical Performance of the New 19-G ViziShot FLEX and 21- or 22-G ViziShot 2 Endobronchial Ultrasoundguided Transbronchial Needle Aspiration Needles. Intern Med 2018.

29. Sakata KK, Midthun DE, Mullon JJ, et al. Comparison of Programmed Death Ligand-1 Immunohistochemical Staining Between Endobronchial Ultrasound Transbronchial Needle Aspiration and Resected Lung Cancer Specimens. Chest 2018;154:827-37.

30. Sakakibara R, Inamura K, Tambo Y, et al. EBUS-TBNA as a Promising Method for the Evaluation of Tumor PD-L1 Expression in Lung Cancer. Clin Lung Cancer 2017;18:527-34.e1.

31. Qin H, Wang F, Liu H, et al. New advances in immunotherapy for non-small cell lung cancer. Am J Transl Res 2018;10:2234-45.

32. Czarnecka-Kujawa K, Yasufuku K. Molecular alterations in non-small-cell lung cancer: perspective for targeted therapy and specimen management for the bronchoscopist. Respirology 2014;19:1117-25.

33. Anraku M, Pierre AF, Nakajima T, et al. Endobronchial ultrasound-guided transbronchial needle aspiration in the management of previously treated lung cancer. Ann Thorac Surg 2011;92:251-5; discussion 255.

34. Tuzi A, Bolzacchini E, Suter MB, et al. Biopsy and rebiopsy in lung cancer: the oncologist requests and the role of endobronchial ultrasounds transbronchial needle aspiration. J Thorac Dis 2017;9:S405-S9.

35. Steinfort DP, Conron M, Tsui A, et al. Endobronchial ultrasound-guided transbronchial needle aspiration for the evaluation of suspected lymphoma. J Thorac Oncol 2010;5:804-9.

36. Erer OF, Erol S, Anar C, et al. Diagnostic yield of EBUSTBNA for lymphoma and review of the literature. Endosc Ultrasound 2017;6:317-22.

37. Gandotra S, Dotson T, Lamar Z, et al. Endobronchial Ultrasound Transbronchial Needle Aspiration for the Diagnosis of Lymphoma. J Bronchology Interv Pulmonol 2018;25:97-102.

38. Wahidi MM, Herth F, Yasufuku K, et al. Technical Aspects of Endobronchial Ultrasound-Guided Transbronchial Needle Aspiration: CHEST Guideline and Expert Panel Report. Chest 2016;149:816-35. 
39. Du Rand IA, Barber PV, Goldring J, et al. British Thoracic Society guideline for advanced diagnostic and therapeutic flexible bronchoscopy in adults. Thorax 2011;66 Suppl 3:iii1-21.

40. Nakajima T, Yasufuku K, Fujiwara T, et al. Recent advances in endobronchial ultrasound-guided transbronchial needle aspiration. Respir Investig 2016;54:230-6.

41. Deshwal H, Avasarala SK, Ghosh S, et al. Forbearance With Bronchoscopy: A Review of Gratuitous Indications. Chest 2019;155:834-47.

42. Mehta AC, Almeida FA. Choose wisely: endobronchial ultrasound-guided transbronchial needle aspiration for sarcoidosis. Chest 2014;146:530-2.

43. Trisolini R, Baughman RP, Spagnolo P, et al. Endobronchial ultrasound-guided transbronchial needle aspiration in sarcoidosis: Beyond the diagnostic yield. Respirology 2019;24:531-42.

44. Gupta D, Dadhwal DS, Agarwal R, et al. Endobronchial ultrasound-guided transbronchial needle aspiration vs conventional transbronchial needle aspiration in the diagnosis of sarcoidosis. Chest 2014;146:547-56.

45. Kumar S, Chandra S. A "ROSE" in every "EBUS" keeps transbronchial lung biopsy away. Chest 2014;146:e97.

46. von Bartheld MB, Dekkers OM, Szlubowski A, et al. Endosonography vs conventional bronchoscopy for the diagnosis of sarcoidosis: the GRANULOMA randomized clinical trial. Jama 2013;309:2457-64.

47. Statement on sarcoidosis. Joint Statement of the American Thoracic Society (ATS), the European Respiratory Society (ERS) and the World Association of Sarcoidosis and Other Granulomatous Disorders (WASOG) adopted by the ATS Board of Directors and by the ERS Executive Committee, February 1999. Am J Respir Crit Care Med 1999;160:736-55.

48. Jeong YJ, Lee KS. Pulmonary tuberculosis: up-todate imaging and management. AJR Am J Roentgenol 2008;191:834-44.

49. Ye W, Zhang R, Xu X, et al. Diagnostic Efficacy and Safety of Endobronchial Ultrasound-Guided Transbronchial Needle Aspiration in Intrathoracic Tuberculosis: A Metaanalysis. J Ultrasound Med 2015;34:1645-50.

50. Berger J, Zamora F, Podgaetz E, et al. Usefulness of lymphoid granulomatous inflammation culture obtained by endobronchial ultrasound-guided transbronchial needle aspiration in a fungal endemic area. Endosc Ultrasound 2016;5:243-7.

51. Sanchez-Cabral O, Martinez-Mendoza D, FernandezBussy S, et al. Usefulness of Endobronchial Ultrasound in Patients with Human Immunodeficiency Virus Infection and Mediastinal Lymphadenopathy. Respiration 2017;93:424-9.

52. Tertemiz KC, Alpaydin AO, Karacam V. The role of endobronchial ultrasonography for mediastinal lymphadenopathy in cases with extrathoracic malignancy. Surg Endosc 2017;31:2829-36.

53. Tournoy KG, Govaerts E, Malfait T, et al. Endobronchial ultrasound-guided transbronchial needle biopsy for M1 staging of extrathoracic malignancies. Ann Oncol 2011;22:127-31.

54. Navani N, Nankivell M, Woolhouse I, et al. Endobronchial ultrasound-guided transbronchial needle aspiration for the diagnosis of intrathoracic lymphadenopathy in patients with extrathoracic malignancy: a multicenter study. J Thorac Oncol 2011;6:1505-9.

55. Harris RM, Arnaout R, Koziel H, et al. Utility of microbiological testing of thoracic lymph nodes sampled by endobronchial ultrasound-guided transbronchial needle aspiration (EBUS-TBNA) in patients with mediastinal lymphadenopathy. Diagnostic Microbiology and Infectious Disease 2016;84:170-4.

56. Maturu VN, Dhooria S, Agarwal R. Efficacy and Safety of Transbronchial Needle Aspiration in Diagnosis and Treatment of Mediastinal Bronchogenic Cysts: Systematic Review of Case Reports. J Bronchology Interv Pulmonol 2015;22:195-203.

57. Yasufuku K, Nakajima T, Fujiwara T, et al. Utility of endobronchial ultrasound-guided transbronchial needle aspiration in the diagnosis of mediastinal masses of unknown etiology. Ann Thorac Surg 2011;91:831-6.

58. Rosenblum MK, Wang SX, Seeley EJ. A mass that has no (EBUS) echo. Respir Med Case Rep 2017;23:18-20.

59. Gella V, Ghana S, Srinivas U. Concurrent diagnostic pericardiocentesis and subcarinal mediastinal lymph node aspiration by EBUS TBNA. European Respiratory Journal 2015;46:PA782.

60. Hohenforst-Schmidt W ZP, Steinheimer M, Rupprecht H, Vogl T, Turner JF, Browning R, Tsakiridis K, Huang H. A New Endobronchial Ultrasound (EBUS) Application for Benign and Malignant Pericardial Effusion (PE) Aspiration: Transbronchial Pericardial Effusion Aspiration (TPEA) with a Regular EBUS Transbronchial (TBNA) Needle under Apneic Nasal Jet-Catheter Ventilation. Journal of Biomedicine 2016;1:9-25.

61. Fournier C, Dhalluin X, Wallyn F, et al. Performance of Endobronchial Ultrasound Elastography in the Differentiation of Malignant and Benign Mediastinal 
Lymph Nodes: Results in Real-life Practice. J Bronchology Interv Pulmonol 2019;26:193-8.

62. Hernandez Roca M, Perez Pallares J, Prieto Merino D, et al. Diagnostic Value of Elastography and Endobronchial Ultrasound in the Study of Hilar and Mediastinal Lymph Nodes. J Bronchology Interv Pulmonol 2019;26:184-92.

63. Nakajima T, Yasufuku K. The techniques of endobronchial ultrasound-guided transbronchial needle aspiration. Innovations (Phila) 2011;6:57-64.

64. Harris K, Dhillon SS. Enhancing Endobronchial Ultrasound Images Using a Water-based Lubricant Technique. Ann Am Thorac Soc 2015;12:1734-6.

65. Rusch VW, Asamura H, Watanabe $\mathrm{H}$, et al. The IASLC lung cancer staging project: a proposal for a new international lymph node map in the forthcoming seventh edition of the TNM classification for lung cancer. J Thorac Oncol 2009;4:568-77.

66. Yasufuku K. Linear Endobronchial Ultrasound. In: Ernst A, Herth FJF. editors. Principles and Practice of Interventional Pulmonology. New York, NY: Springer New York, 2013:185-95.

67. Scholten EL, Semaan R, Illei P, et al. Stylet Use Does Not Improve Diagnostic Outcomes in Endobronchial Ultrasonographic Transbronchial Needle Aspiration: A Randomized Clinical Trial. Chest 2017;151:636-42.

68. Gildea TR, Nicolacakis K. Endobronchial Ultrasound: Clinical Uses and Professional Reimbursements. Chest 2016;150:1387-93.

69. Ernst A, Silvestri GA, Johnstone D. Interventional pulmonary procedures: Guidelines from the American College of Chest Physicians. Chest 2003;123:1693-717.

70. Bolliger CT, Mathur PN, Beamis JF, et al. ERS/ATS statement on interventional pulmonology. European Respiratory Society/American Thoracic Society. Eur Respir J 2002;19:356-73.

71. Kinsey CM, Channick CL. Counterpoint: are $>50$ supervised procedures required to develop competency in performing endobronchial ultrasound-guided transbronchial needle aspiration for lung cancer staging? No. Chest 2013;143:891-3.

72. Folch E, Majid A. Point: are $>50$ supervised procedures required to develop competency in performing endobronchial ultrasound-guided transbronchial needle aspiration for mediastinal staging? Yes. Chest 2013;143:888-91.

73. Mahajan AKK, Sandeep J, Folch E. Pulmonary Perspectives ${ }^{\circledR}$ : Ensuring quality for EBUS bronchoscopy with varying levels of practitioner experience. American
College of Chest Physicians. 2017. Available online: https://www.mdedge.com/chestphysician/article/135227/ society-news/pulmonary-perspectives-ensuring-qualityebus-bronchoscopy. Accessed 02/07/2019 2019.

74. Unroe MA, Shofer SL, Wahidi MM. Training for endobronchial ultrasound: methods for proper training in new bronchoscopic techniques. Curr Opin Pulm Med 2010;16:295-300.

75. Davoudi M, Colt HG, Osann KE, et al. Endobronchial ultrasound skills and tasks assessment tool: assessing the validity evidence for a test of endobronchial ultrasoundguided transbronchial needle aspiration operator skill. Am J Respir Crit Care Med 2012;186:773-9.

76. Stather DR, Maceachern P, Rimmer K, et al. Validation of an endobronchial ultrasound simulator: differentiating operator skill level. Respiration 2011;81:325-32.

77. Konge L, Annema J, Clementsen P, et al. Using Virtual-Reality Simulation to Assess Performance in Endobronchial Ultrasound. Respiration 2013;86:59-65.

78. Almeida FA, Salam S, Mehta AC, et al. Sampling Utility of the Convex Probe Endobronchial Ultrasound Visible Intrapulmonary Lesion. J Bronchology Interv Pulmonol 2018;25:290-9.

79. Erer OF, Cimen P, Unlu M, et al. Four cases of pulmonary thromboembolism diagnosed by endobronchial ultrasound. J Clin Ultrasound 2017;45:441-4.

80. Sariaydin M, Gunay S, Gunay E, et al. Endobronchial ultrasound: an unusual diagnostic tool for pulmonary embolism. Am J Emerg Med 2016;34:684.e1-2.

81. Mahajan AK, Ibrahim O, Shostak E, et al. EBUS-TBNA of pulmonary artery clot. J Bronchology Interv Pulmonol 2014;21:371-3.

82. Harris K, Modi K, Kumar A, et al. Endobronchial ultrasound-guided transbronchial needle aspiration of pulmonary artery tumors: A systematic review (with video). Endosc Ultrasound 2015;4:191-7.

83. Al-Saffar F, Ibrahim S, Seeram V, et al. Use of endobronchial ultrasound to evaluate nonthrombotic endovascular lesions in pulmonary arteries: a systematic review. J Bronchology Interv Pulmonol 2015;22:28-32.

84. Kinsey CM. Endobronchial ultrasound-guidedtransbronchial needle injection for direct therapy of lung cancer. AME Med J 2018;3:74.

85. Fujino K, Ujiie H, Kinoshita T, et al. First Evaluation of the Next Generation Endobronchial Ultrasound System in preclinical models. Ann Thorac Surg 2019;107:1464-71.

86. Patel P, Wada H, Hu HP, et al. First Evaluation of the New Thin Convex Probe Endobronchial Ultrasound 
Scope: A Human Ex Vivo Lung Study. Ann Thorac Surg 2017;103:1158-64.

87. Bousema JE, Dijkgraaf MGW, Papen-Botterhuis NE, et al. MEDIASTinal staging of non-small cell lung cancer

Cite this article as: Avasarala SK, Aravena C, Almeida FA. Convex probe endobronchial ultrasound: historical, contemporary, and cutting-edge applications. J Thorac Dis 2020;12(3):1085-1099. doi: 10.21037/jtd.2019.10.76 by endobronchial and endoscopic ultrasonography with or without additional surgical mediastinoscopy (MEDIASTrial): study protocol of a multicenter randomised controlled trial. BMC Surg 2018;18:27. 